\title{
Spontaneous renal artery dissection associated with sexual intercourse: a case report
}

This article was published in the following Dove Press journal: International Medical Case Reports Journal

\author{
Mohammed Elhassan \\ Shaikh Husnain \\ Raza Mian \\ Department of Internal Medicine, \\ Division of Hospital Medicine, \\ University of California San Francisco \\ (UCSF) Fresno Medical Education \\ Program, Fresno, CA, USA
}

\begin{abstract}
Spontaneous renal artery dissection is a rare cause of renal infarction and can be a diagnostic challenge at times, necessitating high index of suspicion. Other common underlying causes, especially thromboembolic phenomena, need to be considered and investigated first before making this uncommon diagnosis with vascular imaging studies. Very few cases did report strenuous exercise as a predisposing factor for the development of spontaneous renal artery dissection, but we believe that sexual intercourse has not been reported before as an underlying precipitating etiology. We report a case of a young male who presented with renal infarction that started during sexual intercourse and was found to have an angiographically proven renal artery dissection.
\end{abstract}

Keywords: spontaneous renal artery dissection, renal infarction, sexual intercourse

\section{Introduction}

Acute abdominal pain can be a diagnostic challenge, and renal infarction is a known but less common etiology, with only about 165 cases reported over a 30 -year period in one retrospective review. ${ }^{1}$ Renal infarction is more commonly due to thromboembolism, mostly from atrial fibrillation, but also from other rarer causes. ${ }^{1,2}$ Although historically reported to be rare, spontaneous renal artery dissection (SRAD) was found to be the second most common cause of renal infarction after embolism in one recent case series of 35 patients with acute renal infarction. ${ }^{2}$ It is distinct from secondary renal artery dissection due to endovascular intervention or trauma. It can be a diagnostic challenge, with some patients thought to have other diagnoses initially before finally reaching the diagnosis. ${ }^{3,4}$ We report what we believe - to the best of our knowledge - the first reported case of SRAD that occurred during sexual intercourse.

\section{Case presentation}

A 36-year-old white, Caucasian male with past medical history significant only for ulcerative colitis treated with subtotal colectomy about 7 years prior to admission (and subsequently was not put on any medications) presented with sudden onset of right flank pain during sexual intercourse. He described the pain as sharp and severe without prior similar experience. He did not report any penile or sex-related injuries or unaccustomed activity during that sexual activity encounter. Review of systems was unremarkable, except for nausea without vomiting. He denied urinary symptoms. There was no history of smoking or drug use.

In the emergency room, his vital signs were stable without fever, hypertension, or tachycardia. He appeared in moderate distress and only had mild tenderness in the
Correspondence: Mohammed Elhassan Department of Internal Medicine, Division of Hospital Medicine, UCSF, Fresno Center for Medical Education and Research, 155 N Fresno St, Fresno, CA 9370I, USA

Tel +l 5594996500

Fax + I 559499650 I

Email melhassan@fresno.ucsf.edu 
right flank area. Physical examination of other systems was non-revealing with no features of thromboembolic phenomena in the skin or extremities. His complete blood cell count and complete metabolic panel, including serum creatinine, were normal. Sedimentation rate was $25 \mathrm{~mm}$ and C-reactive protein was high at $23 \mathrm{mg} / \mathrm{L}$. Urine analysis was only remarkable for four red blood cells, and urine drug screen was all negative. Electrocardiogram showed normal sinus rhythm. Renal nephrolithiasis was suspected, and patient was taken for computed tomography (CT) scan of abdomen and pelvis, which revealed kidney infarction of about $30 \%-40 \%$ of the right kidney. CT angiography showed stenosis of a branch of right renal artery. He underwent renal angiography, which revealed a patent main right renal artery, but one branch had focal dissection with about $40 \%$ narrowing (Figure 1). Given the preserved kidney function (based on serum creatinine level), the absence of refractory hypertension, and the small diameter of the affected renal vessel, it was felt that medical treatment is a reasonable option for this uncomplicated case of renal infarction. Decision was made to initiate anticoagulation with low-molecular-weight heparin and warfarin and out-patient follow-up with his primary physician and

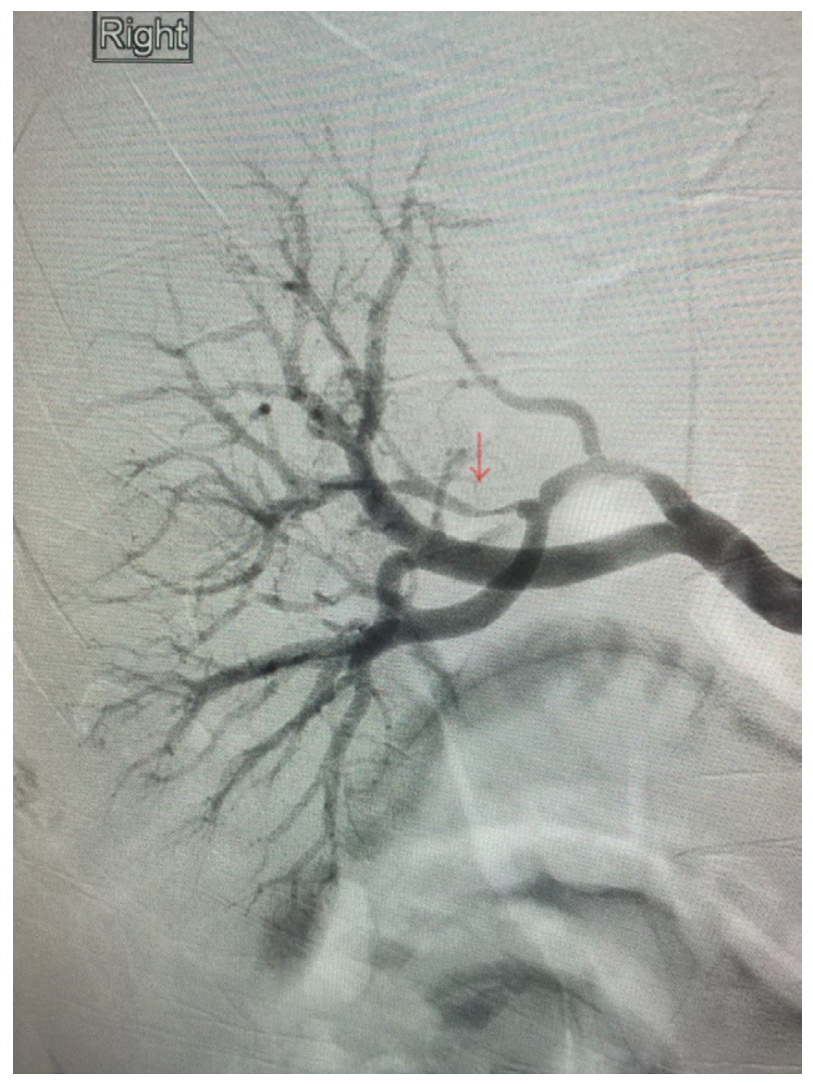

Figure I Renal angiography showing the renal artery dissection in a branch of the right renal artery with about $40 \%$ narrowing (red arrow). anticoagulation clinic in his state, Oregon. His blood pressure and renal function remained normal till the time of discharge.

\section{Discussion}

Renal infarction mostly presents with nonspecific symptoms, but flank pain, nausea, vomiting, and fever are the most common ones reported following renal infarction. ${ }^{1}$ High blood pressure can also be a presenting feature. ${ }^{1,2,5}$ SRAD as a cause of renal infarction can be diagnosed with renal angiography or at autopsy, ${ }^{5}$ but CT angiography can be useful too. Underlying causes and associations with SRAD in prior case reports and case series include middle age, male gender, atherosclerosis, fibromuscular dysplasia, collagen vascular disease, and severe exertion..$^{5-8}$ Nevertheless, many cases have been reported to occur in middle age, otherwise healthy males, like our case. Some physical activities reported to be associated with SRAD are practicing golf, weight lifting, marathon running, and other sporting activities. ${ }^{7,9,10}$ The exact mechanism of dissection in these conditions is not well understood, but thought to be due to stretching of the renal artery and intimal injury with subsequent dissection of the vessel wall and thrombosis. To the best of our knowledge, SRAD after sexual intercourse has not been reported before. The underlying mechanism might be similar to that in SRAD due to other causes of severe physical exertion. Diagnosis needs high index of suspicion, with renal angiography being the gold standard test. In our case, the diagnosis was made relatively early after presentation because renal stone was the working diagnosis; CT of abdomen is the diagnostic test of choice in this situation, and it revealed the unexpected diagnosis of renal infarction - a common presentation for SRAD. It is not clear whether the history of treated ulcerative colitis plays any major pathophysiological role here since his disease was in complete remission, and, at the time of presentation, he was not being actively treated with any medications after his symptoms subsided with surgery.

Recognizing and emphasizing the way SRAD presents and knowing its associated risk factors is important in order for the diagnosis to be made early and the appropriate treatment to be initiated in a timely fashion to minimize its potential complications (eg, worsening kidney function or progressive hypertension). Given the rarity of this condition, with literature discussing only case reports and case series, the best treatment strategy is not known and so should be individualized. Options include surgical intervention, endovascular intervention, medical treatment with antiplatelets or anticoagulants, or expectant management. ${ }^{11-15}$ Many factors play a key role in determining which strategy 
to use in which situation, and these include the extent of the infarction, underlying comorbidities, the presence and absence of hypertension, and the health status of the unaffected kidney. ${ }^{11-16}$ Medical treatment with anticoagulation and control of blood pressure is usually the initial management option in uncomplicated cases, with invasive procedures reserved for complicated cases or patients who failed medical therapy. ${ }^{17}$ In our case, the artery involved was a small segmental branch, not the main artery, making it unamenable to endovascular intervention. It was felt that since his bleeding risk was low, anticoagulation would be reasonable till further follow-up to check his blood pressure and kidney function. Our patient was on a trip to his own state, Oregon, and decided to get his follow-up there.

\section{Acknowledgments}

We would like to thank the patient who agreed to publish the case. Prior to submission of this case report, the patient was contacted to obtain formal informed consent from him to allow us to publish the details of his case as a case report. He gave us the oral permission to publish, reproduce, and distribute the attached Case Report regarding his clinical and medical history. He is aware that the Case Report does not mention his name or address, but it does reflect his medical care, gender, age, and medical history.

\section{Disclosure}

The authors report no conflicts of interest in this work.

\section{References}

1. Antopolsky M, Simanovsky N, Stalnikowicz R, Salameh S, Hiller N. Renal infarction in the ED: 10-year experience and review of the literature. Am J Emerg Med. 2012;30(7):1055-1060.
2. Yoon $\mathrm{K}$, Song SY, Lee $\mathrm{CH}$, et al. Spontaneous renal artery dissection as a cause of acute renal infarction: clinical and MDCT findings. J Korean Med Sci. 2017;32(4):605-612.

3. Dauchy EM, Modica M, Masri NJ. A rare cause of abdominal pain. J La State Med Soc. 2017;169(2):54-55.

4. Kanofsky JA, Lepor H. Spontaneous renal artery dissection. Rev Urol. 2007;9(3):156-160.

5. Edwards BS, Stanson AW, Holley KE, Sheps SG. Isolated renal artery dissection, presentation, evaluation, management, and pathology. Mayo Clin Proc. 1982;57(9):564-571.

6. Harrison EG, Hunt JC, Bernatz PE. Morphology of fibromuscular dysplasia of the renal artery in renovascular hypertension. Am J Med. 1967;43(1):97-112.

7. Im C, Park HS, Kim DH, Lee T. Spontaneous renal artery dissection complicated by renal infarction: three case reports. Vasc Specialist Int. 2016;32(4):195-200.

8. Afshinnia F, Sundaram B, Rao P, Stanley J, Bitzer M. Evaluation of characteristics, associations and clinical course of isolated spontaneous renal artery dissection. Nephrol Dial Transplant. 2013;28(8):2089-2098.

9. Iqbal FM, Goparaju M, Yemme S, Lewis BE. Renal artery dissection following marathon running. Angiology. 2009;60(1):122-126.

10. Thomas MC, Walker RJ, Packer S. Running repairs: renal artery dissection following extreme exertion. Nephrol Dial Transplant. 1999;14(5):1258-1259.

11. Ramamoorthy SL, Vasquez JC, Taft PM, Mcginn RF, Hye RJ. Nonoperative management of acute spontaneous renal artery dissection. Ann Vasc Surg. 2002;16(2):157-162.

12. Mudrick D, Arepally A, Geschwind JF, Ronsivalle JA, Lund GB, Scheel P. Spontaneous renal artery dissection: treatment with coil embolization. J Vasc Interv Radiol. 2003;14(4):497-500.

13. Misrai V, Peyromaure M, Poiree S, Marteau V, Laurian C. Spontaneous dissection of branch renal artery - is conservative management safe and effective? J Urol. 2006;176(5):2125-2129.

14. Pellerin O, Garçon P, Beyssen B, et al. Spontaneous renal artery dissection: long-term outcomes after endovascular stent placement. JVasC Interv Radiol. 2009;20(8):1024-1030.

15. Müller BT, Reiher L, Pfeiffer T, et al. Surgical treatment of renal artery dissection in 25 patients: indications and results. J Vasc Surg. 2003;37(4):761-768.

16. Renaud S, Leray-Moraguès H, Chenine L, Canaud L, Vernhet-Kovacsik $\mathrm{H}$, Canaud B. Spontaneous renal artery dissection with renal infarction. Clin Kidney J. 2012;5(3):261-264.

17. Vitiello GA, Blumberg SN, Sadek M. endovascular treatment of spontaneous renal artery dissection after failure of medical management. Vasc Endovascular Surg. 2017;51(7):509-512.
International Medical Case Reports Journal

\section{Publish your work in this journal}

The International Medical Case Reports Journal is an international, peer-reviewed open-access journal publishing original case report from all medical specialties. Previously unpublished medical posters are also accepted relating to any area of clinical or preclinical science. Submissions should not normally exceed 2,000 words or

\section{Dovepress}

4 published pages including figures, diagrams and references. The manuscript management system is completely online and includes a very quick and fair peer-review system, which is all easy to use. Visit http://www.dovepress.com/testimonials.php to read real quotes from published authors. 